В. А. Шупер // Известия РАН. Серия географическая. - 2006. - № 4. - С. . 7-15.

10. Фрейкин, 3.Г. Николай Николаевич Баранский: научно-популярная литература / З. Г. Фрейкин. - М.: Мысль, 1990. - 126 с.

11. Курнышев, В.В. Региональная экономика. Основы теории и методы исследования: учебное пособие / В.В. Курнышев, В.Г. Глушкова. - 2-е изд., перераб. и доп. — М.: КНОРУС, 2011. — 272 с.

12. Глух Н.А. Институционально-социологическая традиция во Франции. Ф. Перру [Электронный pecypc]: http:/gallery.economicus.ru/cgibin/ frame_rightn.pl?type $=$ school\&links $=. /$ in/perroux/lectures/perroux_11.txt\&img=lectur es_small.gif\&name $=$ oldinstitutionalism. - Дата обращения: 22.04.2015

13. Кейнс, Дж. М. Общая теория занятости, процента и денег / Пер. проф. Н. Н. Любимова. - М.: Гелиос АРВ, 2012. - 352 с.

14. Блюмин И. Г. Американская школа в буржуазной политической экономии // Критика буржуазной политической экономии: В 3 томах. - М.: Изд-во АН СССР, 1962. - Т. I. Субъективная школа в буржуазной политической экономии. - С. 228-430. - VIII, 872 с.

15. Воронцовский, А.В. В.В. Леонтьев - выдающийся экономист XX столетия / А.В. Воронцовский // Вестник Санкт-Петербургского университета. Сер.5. Вып. 1. 2007 - с. 3-10.

Статья отправлена: 16.03.2017 г. (С) Ляхова Н.И., Григорян Д.Р.

ЦИТ: иа117-010

DOI: 10.21893/2415-7538.2016-05-1-010

УДК 658:311..42

\title{
НЕКОТОРЫЕ ОСОБЕННОСТИ РАЗВИТИЯ УЧЕТНО- АНАЛИТИЧЕСКОЙ ДЕЯТЕЛЬНОСТИ ПРЕДПРИЯТИЙ МОРСКОГО ТРАНСПОРТА В СОВРЕМЕННЫХ УСЛОВИЯХ
}

Одесский национальный морской университет. Украина

Konevtseva N.A.

SOME FEATURES OF THE DEVELOPMENT OF ACCOUNTING AND

ANALYTICAL ACTIVITY OF THE MARITIME TRANSPORT COMPANIES IN MODERN CONDITIONS

Odessa National Maritime University. Ukraine

В статье приводится содержание и современное состояние двух подходов в развитии аналитической деятельности предприятий. Более широкий подход связан с исследованиями по сбалансированной системе показателей. $B$ результате приоритеты сместились от финансовых показателей $\kappa$ показателям развития. На первое место выходят показатели, характеризуюшие конкурентоспособность услуг транспорта $u$ конкурентоспособность организащий, представляющих услуги.

В традиционном подходе по-прежнему главными остаются методы оченки резервов. При этом применяемые наборы форм связи результирующих и 
факторных показателей, как правило, не отражают причинно-следственные связи и не могут выполнить функиию модели анализируемого процесса, что приводит к ошибочным выводам по результатам анализа.

С учетом отмеченного, в статье называются показатели, которые в настоящее время могут иметь преимущественное использование. Основой количественных методов анализа для предприятий морского транспорта остаётся применение методов математического моделирования. Оптимизационный подход позволяет решать целье блоки задач, как для системы управления в целом, так и для центров ответственности. Называются составляющие этих блоков задач. Отмечается, что накоплен опыт использования предлагаемого.

Ключевые слова: Сбалансированная Система Показателей, конкурентные преимущества по услугам, конкурентоспособность организации, модельные представления анализируемых процессов.

The article contains the content and current state of the two approaches in the development of the analytical activity of companies. A broader approach is associated with research on a balanced system of indexes. As a result, priorities have shifted from financial indicators to development indicators. On the first place are indicators that characterize the competitiveness of transport services and the competitiveness of organizations that provide services.

In the traditional approach, the main ones remain the methods of reserve estimation. In this case, the applied sets of communication forms of the resulting and factor indexes, usually do not reflect the cause-effect relationships and can not perform the function of the model of the analyzed process, which leads to erroneous conclusions based on the analysis results.

With considering what is noted, the indicators that currently can have preferential use are called in the article. The basis of quantitative methods of analysis for marine transport companies remains the application of methods of mathematical modeling. The optimization approach allows solving entire blocks of tasks, both for the management system and for the responsibility centers. The components of these blocks of tasks are called. It is noted that the experience of using the proposed is accumulated.

Keywords: The Balanced System of Indexes, competitive advantages in services, competitiveness of the organization, the model representation of the analyzed processes.

Постановка проблемы. Среди факторов, отрицательно влияющих на конкурентоспособность экономики Украины, указывается недостаточно развитая транспортная инфраструктура. В числе конкурентных преимуществ экономики нашей страны называется выгодное географическое положение. Сопоставление этих положений говорит о том, что мы вынуждены будем хотя бы совершенствовать управление этой не достаточно развитой транспортной инфраструктурой.

В морской транспортной отрасли Украины имеются и теоретические разработки и некоторый опыт совершенствования управленческой деятельности предприятий. Обеспечение эффективности решений за счет более 
качественной учетно-аналитической составляющей информации процесса управления это доступный и естественный путь.

Задачи исследования. Настоящая работа является продолжением опубликованных ранее работ [4, 5], обобщающих исследования по совершенствованию учетно-аналитической деятельности предприятий. Здесь предпринята попытка на этом фоне обозначить место разработок по анализу результатов, связанных с математическим моделированием в управлении морским транспортом. Работы, посвященные этой теме и формулирующие задачу под таким углом зрения, нам не известны.

Основной материал исследования. Сегодня в работах по анализу результатов работы предприятий можно проследить два подхода: более широкий современный подход и более узкий традиционный подход.

Более широкий тесно связан с исследованиями по Сбалансированной Системе Показателей (ССП) [1-3], что в конце концов привело к формированию новых взглядов на всю учетно-аналитическую и управляющую деятельность предприятия. Более узкий подход традиционно связан с количественными методами анализа результатов работы. Оба эти подхода связаны друг с другом.

В результате система показателей представлена такими составляющими: финансовая, клиентская, внутренние бизнес-процессы, обучение и развитие персонала. Сводка основных показателей внутри этих групп выполнена нами в работе [5]. Преобразование учета на предприятиях сводится к выделению видов учета: бухгалтерский (финансовый), управленческий учет, внутренний аудит. Для решения каких вопросов в управлении используются информация в каждом виде учета также приведено в работе [5]. В итоге приоритеты среди наиболее важных показателей сместились от финансовых показателей к показателям развития. В последнее время на первое место выходят показатели, характеризующие конкурентоспособность товаров и (или) конкурентоспособность организаций. Как отмечает Нивен Пол [2] ССП должна быть системой оценки, системой стратегического управления, инструментом распространения информации. Назначение этой системы широкое, при этом учетная работа должна стать учетно-аналитической, а оперативный анализ неизбежным этапом подготовки в принятии решения.

В традиционном подходе в числе решаемых задач по-прежнему остаются следующие: по каким показателям оценить результаты работы предприятий в новых условиях; какие показатели принять за базу сравнения; какие методы анализа достигнутого применить с целью оценки резервов.

В рамках этого подхода переломный момент мог бы наступить с появлением работы [6], но этого не произошло. Подробности на этот счет изложены нами в [4], эта статья вышла в 2014 году на английском языке по независящим от нас обстоятельствам.

Авторы монографии [6] Раяцкас Р.Л. и Плакунов М.К. аргументировано, убедительно и строго показали трудности выбора форм связи результирующего и факторных показателей. Они показали, что сложившийся за многие годы подход, связанный с применением методов теории индексов, использует чаще всего формы связи, представляющие собой уравнения определения и (или) 
уравнения состава ${ }^{1}$. Такой набор, не содержащий уравнений преобразования, где находит отражение технология анализируемого явления, и уравнений поведения, отражающих характер и качество принятых решений, не может применяться для планирования, прогнозирования, а следовательно для анализа. Другими словами, применяемые наборы уравнений не отражают причинноследственные связи, что приводит к ошибочным выводам по результатам анализа, это убедительно показано в работе [6]. Говоря сегодняшним языком, применяемый набор форм связи не может выполнить функцию модели исследуемого процесса. К сожалению, именно этот подход по-прежнему широко представлен в современной учебной литературе [7].

В управленческой деятельности предприятий морского транспорта таких, например, как перевозочная компания и порт, будут происходить изменения, отражающие выше изложенные тенденции. Некоторые особенности изменений учетно-аналитической работы мы и намерены отразить в этой статье.

1. В ССП финансовые показатели и показатели развития услуг предприятий, в том числе морского транспорта, будут сохраняться и дальше. Однако, на первый план выходят показатели, характеризующие конкурентные преимущества по услугам и конкурентоспособность организации в целом. Поэтому в управленческом учете состояние по этим показателям предстоит отслеживать. Фиксировать и вычислять необходимо такие показатели как время доставки грузов, коммерческую скорость доставки, себестоимость перевозки грузов по направлениям, валовую интенсивность грузовых операций в портах, себестоимость перегрузочных операций по видам грузов и вариантам работ. В числе оценочных могут появиться показатели частных приращений по факторам.

2. В структуре управления портом и в перевозочной компании решающие центры (РЦ) или центры ответственности традиционно всегда выделялись. В порту это группа причалов $\mathrm{c}$ технологией специализированной или универсальной. В перевозочной компании - группа судов или группа направлений (линий). В системе управления - отделы.

3. Что касается количественных методов анализа и оценки резервов, то в теории для предприятий морского и речного транспорта выполнены исследования, которые можно рассматривать как базовые для последующего развития. Разработаны и имели практическое применение математические модели и методы оптимизации решений. В Одесском национальном морском университете (тогда ОИИМФе) много лет такие расчеты выполнялись и в хоздоговорных темах, и в учебном процессе. Выполнялись расчеты и по оптимизации схем доставки грузов для различных видов транспорта. Не вдаваясь в подробности, отметим, что это были работы достаточного масштаба. Все модели и практический опыт их применения можно использовать в совершенствовании аналитической работы.

4. За базу сравнения принимаются оптимальные значения показателей, которые были бы в отчетных условиях. Эти показатели отражают оптимальный

${ }^{1}$ по терминологии Р.Л. Раяцкаса и М.К. Плакунова 
способ организации и фактическую технологию. Как было показано в работе [4], определенные таким образом базовые показатели, компенсируют необходимость использования уравнений преобразования и уравнений поведения [6]. Отчетные условия представлены в модели правыми частями ограничений и коэффициентами при неизвестных в целевой функции и ограничениях.

5. Предпринимательская деятельность - это процесс непрерывного поиска изменений в потребностях (спросе) конечного потребителя услуг. Под конкурентоспособностью организации будем понимать конкурентоспособность услуг, которые эта организация оказывает и конкурентоспособность самой системы управления, то есть структуры, предоставляющей эти услуги потребителю. Суть деятельности системы управления состоит в постоянном отслеживании и анализе условий предоставления транспортных услуг предприятиями морского транспорта у конкурентов и у себя. Также в этой системе принимаются решения по управлению своими преимуществами и поиск новых преимуществ. Поэтому учетно-аналитическая деятельность и требует изменений, о которых сказано выше, а вся система управления, в том числе эта деятельность, должна использовать идеи оптимизации. О преимуществах этого подхода сказано достаточно. Здесь обратим внимание на то, что используя модельные представления анализируемого процесса (как базовую модель) можно решать не одну, а много аналитических задач различного содержания.

Так, если базовой задачей считать задачу с содержанием «Анализ эффективности использования флота», то она «обрастает» дополнительными задачами содержательно отличными от основной, но решаемыми с помощью одной и той же модели. В перечень дополнительных задач можно включить такие:

- Анализ эффективности использования флота на направлении (на линии, в регионе),

- Анализ эффективности использования судов типа (группы судов по специализации или разнотипных),

- Анализ резервов повышения эффективности использования флота компании за счет изменения условий, например, затрат времени, расходов, фрахтовых ставок и т.п.

В «блок» задач по планированию могут войти, например, задачи с таким содержанием: определение оптимальных значений основных плановых показателей на перевозках конкретных грузов; определение оптимальных значений плановых показателей работы флота за период; анализ напряженности планового задания для флота компании.

Темы, приведенные нами здесь, это реальная тематика дипломного и курсового проектирования в ОНМУ в период 1975-1990 гг. ${ }^{2} * *$.

По аналогии с приведенным выше перечнем задач, можно получить «блок»

Коневцева Н.А. Анализ эффективности использования флота пароходства. Методические указания по выполнению дипломного проекта. Одесса ОИИМФ, 1986. - с. 24 
задач на базе оптимизации работы порта, их решение можно использовать в совершенствовании аналитической деятельности этого предприятия. Этот подход использован в работах О.Б. Гириной [8].

Таким образом, основания для совершенствования учетно-аналитической работы на основных предприятиях морского транспорта имеются.

Выводы. На фоне обобщения результатов по совершенствованию учетноаналитической деятельности предприятий морского транспорта показано:

$>$ в составляющих Сбалансированной Системы Показателей, кроме принятых ранее, названы те, которые могут иметь преимущественное использование в дальнейшем;

система управления предприятиями морского транспорта имеет традиции выделения решающих центров (центров ответственности);

основой количественных методов анализа, как для перевозочной компании, так и для порта, является применение методов математического моделирования;

в качестве базы сравнения предлагается использовать оптимальные значения показателей в отчетных условиях;

использование оптимизационного подхода позволяет решать целые блоки задач, как для системы в целом, так и для центров ответственности.

Литература.

1. Каплан, Нортон. Сбалансированная система показателей: от стратегии к действию / Пер. с англ. - М.: ЗАО «Олимп-Бизнес», 2003, - 294с.

2. Нивен Пол Р. Сбалансированная Система Показателей: - Шаг за шагом: максимальное повышение эффективности и закрепление полученных результатов / Пер.с англ. - Днепропетровск: Баланс Бизнес Букс, 2004. - 328 с.

3. Браун, Марк Грэм. Сбалансированная система показателей: на маршруте внедрения / Марк Грэм, Браун, Пер. с англ. - М.: Альпина Бизнес Букс, 2005. $224 \mathrm{c}$.

4. Коневцева Н.А. О применении количественных методов в анализе экономических показателей // «Актуальні проблеми Економіки» - 2014 - №9 (159), - C. 495-499

5. Коневцева Н.А. Особенности учетно-аналитической работы в управлении предприятием в современных условиях // Сб. научн. трудов World. - 2015. - Том 18, вып. 1(38). - С.14-22

6. Раяцкас Р.Л., Плакунов М.К. Количественный анализ в экономике - М.: Наука, 1987. - 391 с.

7. Петряєва З.Ф. Організація i методика економічного аналізу: навч.посібник / З.Ф.Петряєва, Г.Т. Хмеленко. - Харьків: Вид. ХИЕУ, 2008. 480c.

8. Гирина О.Б. Методы определения и анализа использования пропускной способности портов басейна. Автореф. дис....канд. экон. наук / Гирина Ольга Борисовна. - Одесса: ОНМУ, 1993. - 20с. 